\title{
DIVERSITY IN HLA CLASS I AND CLASS II IN KIDNEY DONORS AND RECIPIENTS ACCORDING TO RACE IN KWAZULU-NATAL (SOUTH AFRICA) - IMPLICATIONS FOR TRANSPLANTATION
}

\author{
Assounga AGH ${ }^{1}$, Schreiber $V^{1}$, Allen $V^{1}$, Anley $\mathbf{D}^{2}$. \\ 1 - Department of Nephrology, Inkosi Albert Luthuli Hospital, University of KwaZulu-Natal, Durban, South Africa \\ 2 - Tissue Immunology Laboratory, South African National Blood Services, Durban, South Africa
}

\begin{abstract}
HLA matching of donors and recipients plays a major role in the success of organ transplantation. Race differences in HLA have been reported elsewhere.

Aim: To analyse the diversity of HLA Class I and Class II among kidney donors and recipients according to race.

Methods: This is a retrospective study of HLA types of renal patients and kidney donors attending the Renal Unit at Addington and Inkosi Albert Luthuli Central Hospitals from 1985 to 2002. Class I HLA typing was done using serological methods while Class II HLA typing was done using serological or molecular methods at the Tissue Immunology Laboratory, South African National Blood Services, Durban, South Africa. Files for 470 individuals were reviewed. There were 143 Blacks, 169 Indians, 88 Whites and 70 Coloureds. All the files were included and analysed according to race.
\end{abstract}

Results: HLA A locus, 18 distinct antigens were recorded in Black patients. In Indians, 17 antigens were recorded. In Whites, 16 antigens were observed and the most frequent were A2 (29\%) and A1 (17\%). For the HLA B locus, 29 antigens were recorded in Blacks with the two most frequent being B58 (13\%) and B44 (12.5\%). In Indians, 28 antigens were recorded. For DR locus 29 distinct antigens were recorded.

Conclusion: Race differences in the profile of HLA types are observed. This may render difficult HLA matching between donors and recipients in organ transplantation.

\section{INTRODUCTION:}

Major Histocompatibility Complex (MHC) Class I and Class II matching of donors and recipients plays an important role in the success of organ transplantation [1,2]. HLA diversity has been reported with the most diversity amongst Blacks [3-5]. High levels of diversity was found in Blacks living in Africa (The Gambia, South Africa, Malawi) and in Blacks in the diaspora such as from Martinique in the Caribbean and African Americans in the USA [3,6,7]. In a previous report from Durban, differences in the prevalence of certain HLA antigens between children with nephrotic syndrome have been observed in Black Africans and Indians [8].
The association of HLA and diseases are widely reported [9-12]. Certain HLA antigens have been associated with renal disease and cardiovascular diseases, especially certain phenotypes are associated with cardiovascular hypertrophy $[13,14]$. Other associations include, for instance, HLA A3 which is associated with low prevalence of atheromatosus in subjects with type 2 diabetes mellitus [15]. In this study, we analyse head to head HLA diversity between race groups (Black Africans, Whites, Indians and Coloureds(individuals of mixed ancestry)) in the same region.

The aim of this study is to analyse the diversity of HLA Class I and II in kidney donors and recipients according to race and to discuss implications on kidney transplantation 
within and across races. Knowledge of HLA diversity among race groups may help predict how long a patient is likely to wait for an organ. Also, it may help forecast the prevalence of certain diseases in our population and therefore could be a useful tool for planning medical resources.

\section{MATERIALS AND METHODS:}

This a retrospective study examining the HLA type of kidney donors and recipients from the transplantation database at the division of Nephrology at Addington Hospital and Inkosi Albert Luthuli Hospital (IALCH) in Durban, South Africa.

\section{MATERIALS:}

All files of kidney donors and recipients attending Addington Hospital and IALCH were included from 1985-2002. Kidney donors include living related (2/3) and cadaver (1/3). A total of 474 individual files were recorded. They were analysed according to HLA type and race. There were 143 Blacks, 169 Indians, 88 Whites and 74 Coloureds (individuals of mixed ancestry).

\section{METHODS:}

All tissue typing tests on blood collected by venesection on kidney recipients and donors described above, were performed at The Laboratory of Immunology, South African Blood Bank Services, Durban, South Africa.

MHC Class I typing was done with serological methods as previously described [16]. MHC Class II HLA typing was done using serological and molecular methods as previously described [17]. Class I typing was performed using serology typing trays. Molecular typing for HLA Class II (DR and DQ) was performed using the SSP method until 2001. Thereafter the SSO method was used [18].

All samples collected at the same period were subjected to the same laboratory processes. Results of all patients HLA typing for MHC Class I (A, B) and MHC Class II (DRBeta and DQBeta1) loci were included and analysed according to race. Results were analysed using Instat 2 programme (Graphpad, San Diego, CA, USA). $\mathrm{X}^{2}$ or analysis of variance were used to compare various groups.

\section{RESULTS:}

For HLA A locus: 18 distinct alleles were recorded in Blacks with the two most frequent being A30 (19\%) and A2 (16\%). In Indians, 17 alleles were recorded, A2 (20\%) and A24 $(18 \%)$ were the most frequent. In Whites, 16 alleles were observed and the most frequent were A2 (29\%) and A1 (17\%) (Fig 1), Table 1.
For the HLA B locus: 29 alleles were recorded in Blacks with the two most frequent being B58 (13\%) and B44 $(12.5 \%)$. In Indians, 28 alleles were recorded and B35 $(16 \%)$ and B57 (10\%) were the most frequent. In Whites, 31 alleles were observed and the most frequent were B7 $(17 \%)$ and B8 (15\%). Certain HLA alleles (eg, HLA B35) were statistically more frequent in one race group: $16 \%$ in Indians, but are rare in other races: $7 \%$ in Whites and 5\% in Blacks $(\mathrm{p}<0.05)$ (Fig 2, Table 1).

For DR locus: 29 distinct alleles were recorded. In Blacks 21 alleles were recorded with the most frequent alleles being DR 11 (20\%). In Indians, 21 haplotypes were recorded, and DR 2 and DR 7 were the most frequent. In Whites, 10 haplotypes were observed and the most frequent were DR 2 and DR 0301 (Fig 3, Table 1).

For DQ locus: 16 alleles were observed. In Blacks, 13 alleles were recorded with the most frequent being haplotype DQ 0602 (17\%). In Indians, 13 alleles were recorded, DQ 0601 being the most frequent. In Whites, seven alleles were observed, the most frequent being DQ 0301 and DQ 6.

Certain alleles (eg, DR 15) were frequent in one race group: $11 \%$ in Indians but are rare in another races: $4 \%$ in Blacks (Fig 4).

Table 1 highlights the main alleles with the most difference between races, while Figures 1-4 reveal the wide difference in the allele distribution between race groups in our population.

\section{DISCUSSION:}

Class I and Class II HLA alleles are diverse in the South African population. Race differences in the profile of HLA types are observed for both A, B, DR and DQ loci. There are similarities with reports from individuals living on other continents [3,6,7]. Diversity among our different races resembles reports from other regions. In Martinique in the Caribbean amongst the population of Black ancestry, the most prevalent alleles of A locus are A30, A34 and A66 as in our Black African population [6]. B15, B35 and DR $\mathrm{B} 1$ are the more prevalent for the B and DR in our Black population. In the US Cao et al analysing the frequency of HLA A, B and C found 46, 100 and 32 respectively, and in African Americans is maximal at all while the lowest was found in Caucasians [6].

The role of HLA goes beyond the matching for organ transplant. The association of HLA and disease is widely reported [20-22]. Recently a less severe HIV infection has been associated with certain HLA B types [23].

Our population includes both patients and healthy donors. This is the closest we could get to the general population. We still need to confirm these results in a truly representative sample of the population. However, the same is applicable to all races. We have observed statistically significant differences between races, and by comparing have observed 
a similarity between our results and the general population. Race differences in the profile of HLA types are observed. Although kidney donation can be done across racial lines, the contribution of kidneys from various race groups is variable. We must encourage all race groups to contribute to the kidney donor pool to improve HLA matching [1,2]. Furthermore, kidney donation is based only on major histocompatibility complex. There may be significant difference in minor histocompatibility genes that are not accounted for. Diversity in genes involved in the processing of peptides presented by MHC Class I proteasome genes and genes for peptide transport associated proteins (TAP) have been reported [24,25]. This may render difficult HLA matching between donors and recipients in organ transplantation in South Africa.

Several reports have indicated differences in racial groups. Wadee \& Du Toit revealed there were HLA differences within the Indian population (hindus, muslims, tamils) living in Johannesburg (South Africa) [26]. A linkage disequilibrium was found in Aw33, B44, B35, Cw4, B7, and $\mathrm{Cw} 7$ antigens. Antigen Aw34 was absent in these populations. The same was found in the Indian population in this study. Modiba et al., reported difficulty in having a good match amongst the South African Black population resulting in a less favourable outcome [27]. Du Toit et al in a report on MHC Class I revealed variation in Black African, Coloured and Caucasians [5]. Martell et al reported the HLA Class II alleles DRw8 and DRw14 were only observed in a mixed ancestral South African population [28].

The Coloured population in South Africa is formed of population of mixed origin and the San people [24]. One would expect to have the diverse alleles found in other race groups plus alleles present in the San people. Similar observations were reported in Latin America highlighting the complexity of HLA profile in a population of mixed origin [29]. This may render difficult HLA matching between donors and recipients in organ transplantation.

In our transplant programme, living related transplantation is the most practised (2/3). As we are striving to increase the percentage of cadaver transplant, it is important that the increase of cadaver donors occur for all the race groups to maintain or improve HLA matching between donors and recipients. Currently most cadaver donors are from White communities. White cadaver donors represent $2 / 3$ while the most recipients of cadaver donors are from the Black population. Barriers to transplantation amongst Blacks and Indians needto be identified and addressed to increase the number of transplants and improve the outcome. Otherwise, the increase in the number of cadaver transplants in Black and Indians would occur at the expense of HLA matching, therefore compromising the outcome.
Table 1: Frequency of a selection of HLA alleles according to race

\begin{tabular}{|c|c|c|c|c|c|}
\hline $\begin{array}{c}\text { HLA } \\
\text { type }\end{array}$ & $\begin{array}{c}\text { Blacks } \\
(\%)\end{array}$ & $\begin{array}{c}\text { Whites } \\
(\%)\end{array}$ & $\begin{array}{c}\text { Indians } \\
(\%)\end{array}$ & $\begin{array}{c}\text { Coloureds } \\
(\%)\end{array}$ & \\
\hline A2 & 16 & 29 & 20 & 22 & \\
\hline A24 & 3.5 & 7.5 & 17.5 & 11 & \\
\hline A30 & 19 & 2.9 & 1.1 & 7 & $(\mathrm{p}<0.0001)$ \\
\hline B7 & 8 & 17 & 8.8 & 12 & \\
\hline B35 & 5 & 6.8 & 16.4 & 8.8 & \\
\hline B58 & 13 & 2.8 & 1.7 & 6 & \\
\hline DR2 & 3 & 6 & 12.6 & 6.4 & $(\mathrm{p}<0.001$ \\
\hline DR4 & 6 & 12.9 & 11.7 & 12.8 & \\
\hline DR11 & 17 & 6.2 & 4.4 & 7.2 & \\
\hline
\end{tabular}

\section{REFERENCES}

1. Schnitzler MA, Hollenbeach CS, Cohen DS, et al. The economical implications of HLA matching in cadaveric renal transplantation. New England J. Med. 1999; 341: 1440-6.

2. Chelluri LK, Vasantha A, Ratnakar KS. Impact of Ethnicity, Donor status and HLA matching on Renal allograft survival: A single center study. Saudi J Kidney Dis Transplant. 2009;20:995-997.

3. Sanchez-Mazas A. African diversity from the HLA point of view: influence of genetic drift, geography, linguistics, and natural selection. Hum Immunol 2001; 62: 937-48.

4. Hill AVS, Allsopp CEM, Kwiatkowski D et al. Extensive genetic diversity in the HLA class II region of Africans, with a focally predominant allele, DRB1*1304. Proc Natl Acad Sci USA 1992, 89: 2277-81.

5. Du ToitED, MacGregor KJ, Taljaard DG, Oudshoorn M. HLA-A, B, C, DR and DQ polymorphisms in three South African population groups: South African Negroes, Cape Coloureds and South African Caucasoids. Tissue Antigens 1988; 31: 109-25.

6. Bera O, Cesaire R, Quelvennec E et al. HLA class I and class II allele and haplotype diversity in Martinicans. Tissue Antigens 2001; 57: 200-7. 
7. Cao K, Hollenbach J, Shi X, Shi W, Chopek M, Fernandez-Vina MA. Analysis of the frequencies of HLA-A, B, and C alleles and haplotypes in the five major ethnic groups of the United States reveals high levels of diversity in these loci and contrasting distribution patterns in these populations. Hum Immunol. 2001; 62: 1009-30.

8. Bhimma R, Hammond MG, Coovadia HM, Adhikari M. Connolly CA. HLA class I and II in black children with hepatitis B virus-associated membranous nephropathy. Kidney Int. 2002; 61:1510-5.

9. Mc Cluskey J, Peh CA. The human leucocyte antigens and clinical reticulocyte antigen and clinical medicine: an overview. Rev. Immunogenetics1999: 1; 3-20.

10. Stanescu HC, Arcos-Burgos M, Medlar A et al. Risk HLA-DQA1 and PLA2R1 alleles in adiopathic Membranous Nephropathy. N. Eng. J. Med. 2011;364:616-626.

11. $\mathrm{Lv} \mathrm{J}, \mathrm{Hou} \mathrm{W}$, Zhou X. et al., Interaction between PLA2R1 and HLA-DQA1 variants associates with anti - PLA2R antibodies and membranous nephropathy. JASN 2013; 24:1190-1192.

12. Meryem A, Noureddine B, Ouaffaa MS et al., HLA-B27 subtypes distribution among maroccan patients with ankylosing spondylitis. Am. J. Med. Biol. Res. 2013; 1:28-32

13. Dogan Y, Ural D, Domanic N, Yilmaz E. Relation of HLA antigens and myocardial infarction. Anadolu Kardiyol Derg 2001;1: 80-4, AXIII.

14. Diamantopoulos EJ, Andreadis EA, Vassilopoulos $\mathrm{CV}$ et al. HLA phenotypes as promoters of cardiovascular remodeling in subjects with arterial hypertension. J Hum Hypertens 2003;17: 63-8.

15. Diamantopoulos EJ, Andreadis EA, Kakou MG et al. Association of the HLA antigens with early atheromatosis in subjects with type 2 diabetes mellitus. Int Angiol 2002; 21: 379-83.

16. Lee JH, Lias M, Deng CT et al. A one step monoclonal antibody typing procedure that simplifies HLA class I and class II typing. Tissue Antigens 1994; 44: 34-42.

17. Dyer PA, Martin S. Techniques used to define human MHC antigens: serology. Immunol. Lett. 1991; 29:1521.

18. Takemoto SK, Terasaki PI. Evaluation of the transplant recipient and donor :molecular approach to tissue typing, flow cytometry and alternative approaches to distributing organs. Curr Opin Nephrol Hypertens 1997; 6: 299-303.
19. Oudshoorn M, Martell RW, Arendse B and du Toit ED. Unusual HLA-DR, DQ haplotypes found in South African families of black, Asian Indian, and mixed ancestral origin. Hum Immunol. 1991; 31:149.

20. Chu CC, Lin M, Nakajima F et al. Diversity of HLA among Taiwan's indigenous tribes and the Ivatans in the Philippines. Tissue Antigens 2001; 58: 9-18.

21. Ivanova M, Spassova P, Michailova A, Naumova E. Distributions of HLA class I alleles and haplotypes in Bulgarian-contribution to understanding the origin of the population. Tissue Antigens 2001; 57: 208-15.

22. Donner H, Tonjes RR, Bontrop RE, Kurth R, Usadel $\mathrm{KH}$, Badenhoop K. MHC diversity in Caucasians, investigated using highly heterogeneous noncoding sequence motifs at the DQB1 locus including a retroviral long terminal repeat element, and its comparison to nonhuman primate homologues. Immunogenetics 2000; 51: 898-904.

23. Kiepiela P, Leslie AJ, Honeyborne I et al., Dominant influence of HLA B in mediating the potential coevolution of HIV and HLA. Nature, 2004; 432: 76974.

24. Yu MC, Haung CM, Wu MC, Wu JY, Tsai FJ. Association of TAP2 gene polymorphisms in chinese patients with rheumatoid arthritis. Clin. Rheumatol. 2004; 23: 35-9.

25. Dogru D, Ozbas Gerceker F, Yalcin E et al. The role of TAP1 and TAP2 gene polymorphism in idiopathic bronchiectasis in children. Pediatr. Pulmo. 2007; 42: 237-41.

26. Wadee AA, du Toit ED. HLA frequencies in the Indian population of Johannesburg. S. Afr. Med.J.1989; 76: 331-4.

27. Modiba MC, Ngcobo TK, Wolf JS, Morse R, du Toit ED. HLA-A,B and DR antigens in renal transplantation. A further report on the Northwestern and MEDUNSA experience. S.Afr.J.Surg.1994; 32: 99-102.

28. Martell RW, Arendse B, Jacobs M, Du Toit ED. HLA class II specificities and haplotypes in South Africa detected using polymerase chain reaction and sequence-specific oligonucleotide typing. Tissue Antigens.1991; 38: 95-8.

29. Arrieta-Bolanos E, Madrigal JA, Shaw BE. Human leukocyte antigen profiles of Latin American populations: Differential admixture and its potential and its potential impact on hematopietic stem cell transplantation. Bone Marrow Research; Vol. 2012, Article ID 136087, 13 pages. 


\section{HLA A Locus}

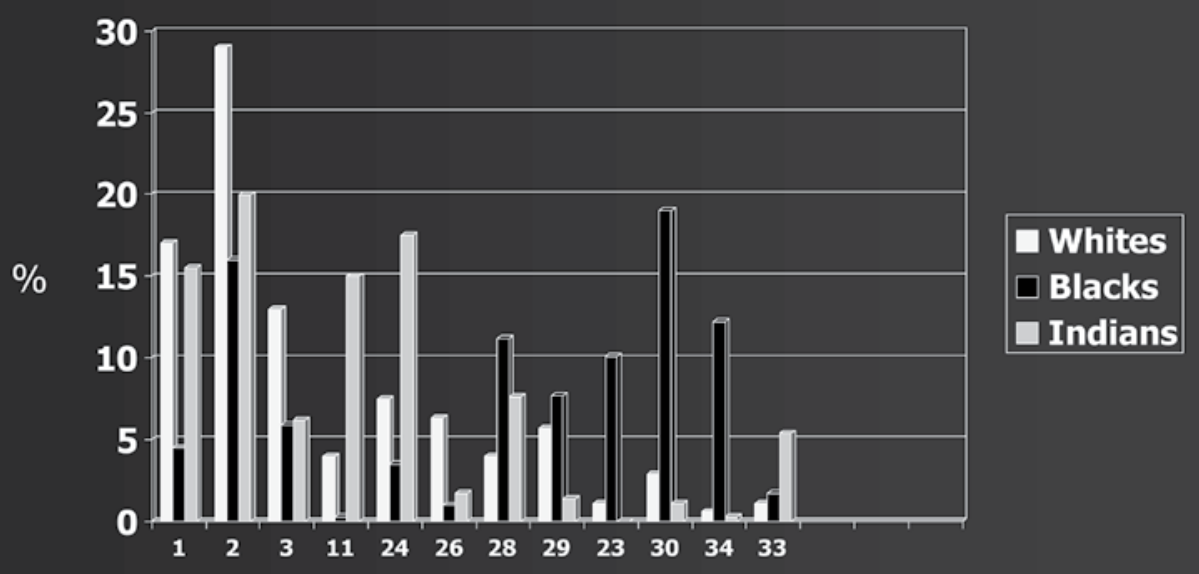

HLA-A haplotypes

Figure 1 Frequencies of HLA-A haplotypes according to race

\section{HLA B Locus}

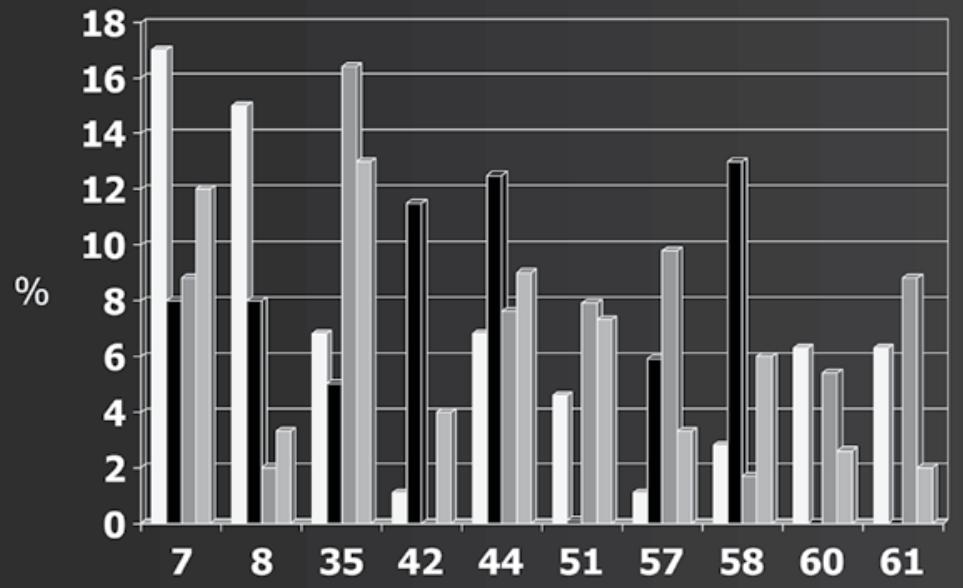

Whites

$\square$ Blacks

$\square$ Indians

c Coloured

HLA B Haplotypes 


\section{DR Locus}

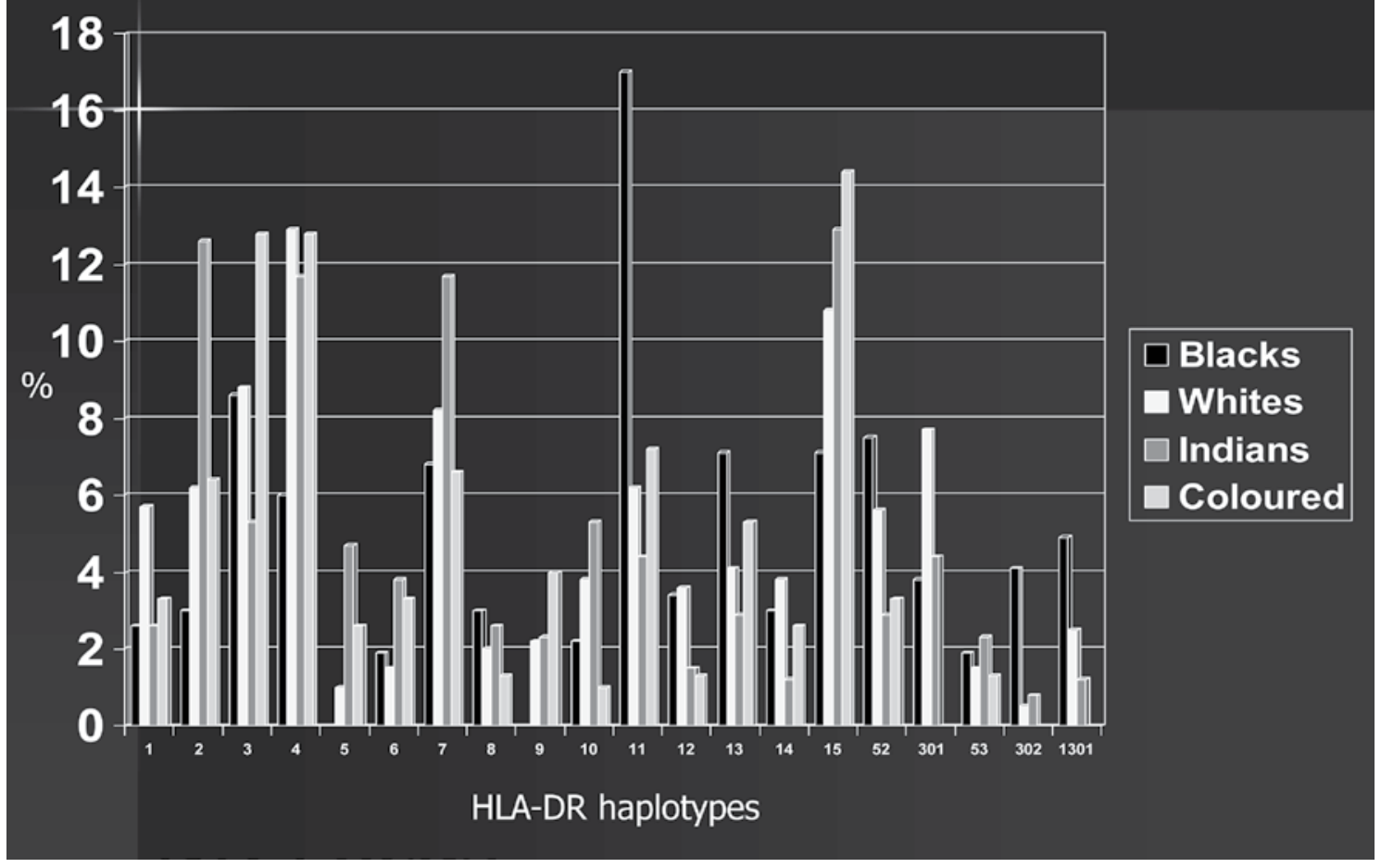

Figure 3 Frequencies of HLA-DR haplotypes according to race

\section{DQ Locus}

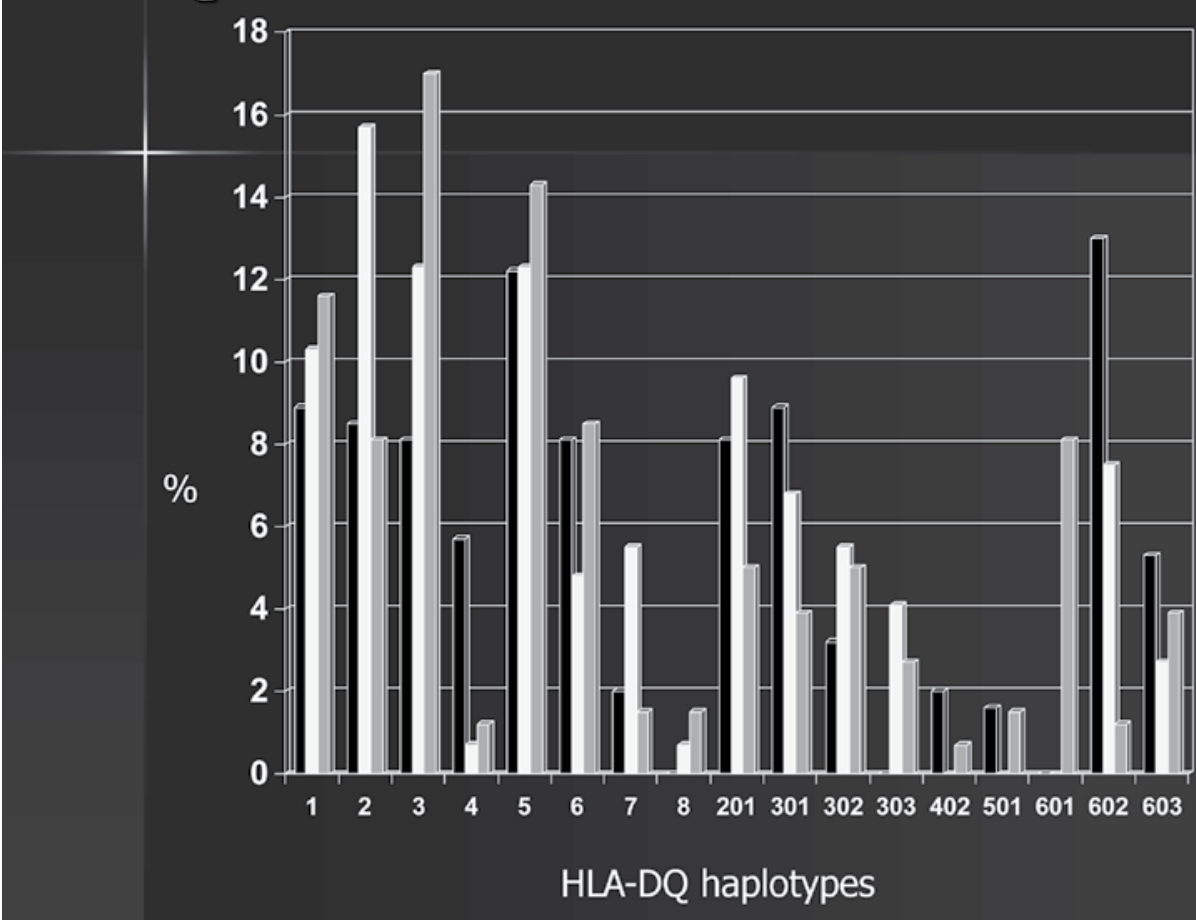

\section{$\square$ Blacks \\ Whites \\ 口Indians}

HLA-DQ haplotypes 